University of New Hampshire

University of New Hampshire Scholars' Repository

Inquiry Journal 2020

Inquiry Journal

Spring 4-4-2020

\title{
Using Magnetostratigraphy to Find the Cretaceous-Paleogene Boundary in La Colonia Formation, Patagonia, Argentina
}

Peter Haber

University of New Hampshire

Follow this and additional works at: https://scholars.unh.edu/inquiry_2020

\section{Recommended Citation}

Haber, Peter, "Using Magnetostratigraphy to Find the Cretaceous-Paleogene Boundary in La Colonia Formation, Patagonia, Argentina" (2020). Inquiry Journal. 4.

https://scholars.unh.edu/inquiry_2020/4

This Article is brought to you for free and open access by the Inquiry Journal at University of New Hampshire Scholars' Repository. It has been accepted for inclusion in Inquiry Journal 2020 by an authorized administrator of University of New Hampshire Scholars' Repository. For more information, please contact

Scholarly.Communication@unh.edu. 


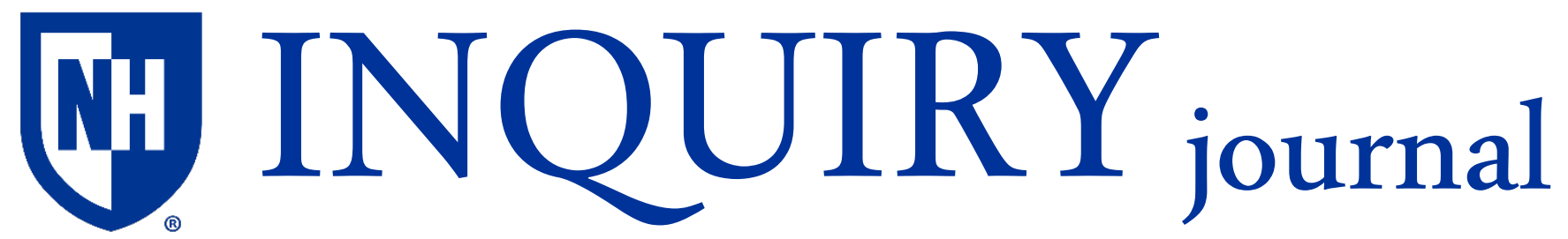

www.unh.edu/inquiryjournal

2020

\section{Research Article}

\section{Using Magnetostratigraphy to Find the Cretaceous-Paleogene Boundary in La Colonia Formation, Patagonia, Argentina}

\section{-Peter Haber}

Approximately 66 million years ago (Clyde et al., 2016), an asteroid collided with the Yucatan Peninsula (Schulte et al., 2010). The effects of this event, which marks the end of the Cretaceous period, were felt around the globe. It induced earthquakes and tsunamis around the impact site. Material released into the atmosphere caused acid rain and blocked sunlight, which caused global temperatures to cool. This cascading sequence of events also caused one of the largest mass extinctions in the history of Earth. Photosynthesizing organisms, such as phytoplankton, that form the base of the food web, suffered high rates of extinction (Aberhan et al., 2007), and the non-avian dinosaurs, at the other end of the food chain, went extinct (Schulte et al., 2010). Other victims included groups of flying and aquatic reptiles, and ammonites, a type of mollusk. This event is preserved in the geologic record and known as the Cretaceous-Paleogene (K-Pg) boundary.

The geologic record refers to the features of rocks that preserve information about the history of Earth. Records of the K-Pg boundary appear in layers of sedimentary rock called strata. These are laid down over time, resulting in a series of strata with the youngest at the top and the oldest at the bottom. Exploring the $\mathrm{K}-\mathrm{Pg}$ boundary is just one example of how the geologic record is used to study our planet's 4.6-billion-year history.

Evidence of the K-Pg extinction and asteroid impact, such as the disappearance of certain species of fossils and deposits of debris from the impact, were recorded in the

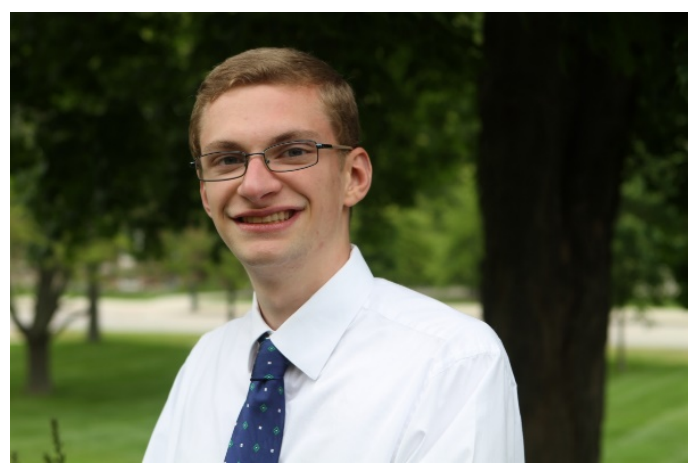

The author, Peter Haber. Photo credit: Randy Schroder sediments as they were laid down as strata at that time.

This creates a boundary in the sequence of strata. This boundary is not always preserved in rocks that formed at this time but does appear in many formations globally. As an Earth sciences major with a strong interest in geology and its application to studying the history of Earth, I was intrigued by the KPg boundary, and it became the focus of my undergraduate research.

I first connected with my mentor, Dr. William Clyde, at the recommendation of my academic adviser during my first year at the University of New Hampshire (UNH). Dr. Clyde's research focuses on the history of Earth, and one of his ongoing research projects is to explore the K-Pg extinction. I joined his 
research team in my first year, and the following summer I conducted a large-scale research project primarily through a summer research fellowship from the McNair Scholars Program. This program is designed for students from underrepresented groups (including low-income students who will be in the first generation in their families to graduate college, such as myself) who are interested in pursuing a graduate education.

My project sought to identify the K-Pg boundary in samples taken from La Colonia Formation in Patagonia, Argentina. This is part of a larger project led by Dr. Clyde and his colleagues in this region. Once a K-Pg boundary site is identified, it can be used to learn more about the mass extinction. Fossils in that formation can be examined layer by layer to determine how the ecosystem was affected by the asteroid impact. These may include microfossils, such as pollen grains, in addition to larger fossils, such as bones of animals.

It is important to understand the impact of these past events in order to understand how our planet works. Specifically, studying the K-Pg boundary can help us understand how Earth responds to catastrophic events. My work to identify the K-Pg boundary in samples from La Colonia will help us better understand the mass extinction, especially how prevalent it was in South America and the extent to which biodiversity in that area suffered.

\section{Background: Exploring the K-Pg Boundary in South America}

The discovery of iridium, which is a metal common on asteroids but uncommon on Earth, at the KPg boundary in formations in Italy, Denmark, and New Zealand led Alvarez et al. (1980) to first propose that an asteroid impact may have caused the K-Pg mass extinction. In 1991, the Chicxulub crater was discovered on the Yucatan Peninsula in Mexico (Hildebrand et al., 1991). Though the crater is approximately $180 \mathrm{~km}$ in diameter, it was not previously noticed because over time it had filled with sediment. Geologists studying the region discovered it through data from gravity and magnetic field measurements and determined the crater's date of formation based on the age of the surrounding rocks. The crater's age was then correlated to the K-Pg boundary and determined as the likely site of the asteroid impact that caused the K-Pg extinction.

There are few known K-Pg boundary records in South America, primarily because the boundary has not been studied there as much as it has been on other continents. Therefore, the effects of the Chicxulub impact and the magnitude of the mass extinction in South America are poorly understood. It is important that geologists identify more K-Pg boundary records on the continent so that we can better understand the extent to which the mass extinction occurred there, the effects of the impact, and how quickly ecosystems recovered from the extinction. 
The sites in South America that show evidence of the boundary include ones in Argentina, Colombia, and Brazil (Scasso et al., 2005; Albertão and Martins, 1996; Renne et al., 2018). La Colonia Formation in Argentina is composed of sedimentary rock with deposits from lake and stream or river environments (Figure 1). It also contains fossils of many animal and plant species (Cúneo et al., 2014). The environment in this region is a desert, allowing much of the bedrock to be exposed at the surface. This makes it easier to observe the geology of the area and collect samples.

\section{Background: Identifying the K-Pg Boundary}

Several methods are used to find evidence of the K$\mathrm{Pg}$ boundary in rock formations. One method is to identify the impact layer through physical examination or analysis of strata. If an impact layer is found, all rock below that layer was formed before the impact event, whereas everything above it was formed afterward. These impact layers usually contain high concentrations of iridium. Other impact evidence in strata include a red clay

layer, tsunami deposits, spherules (small circular

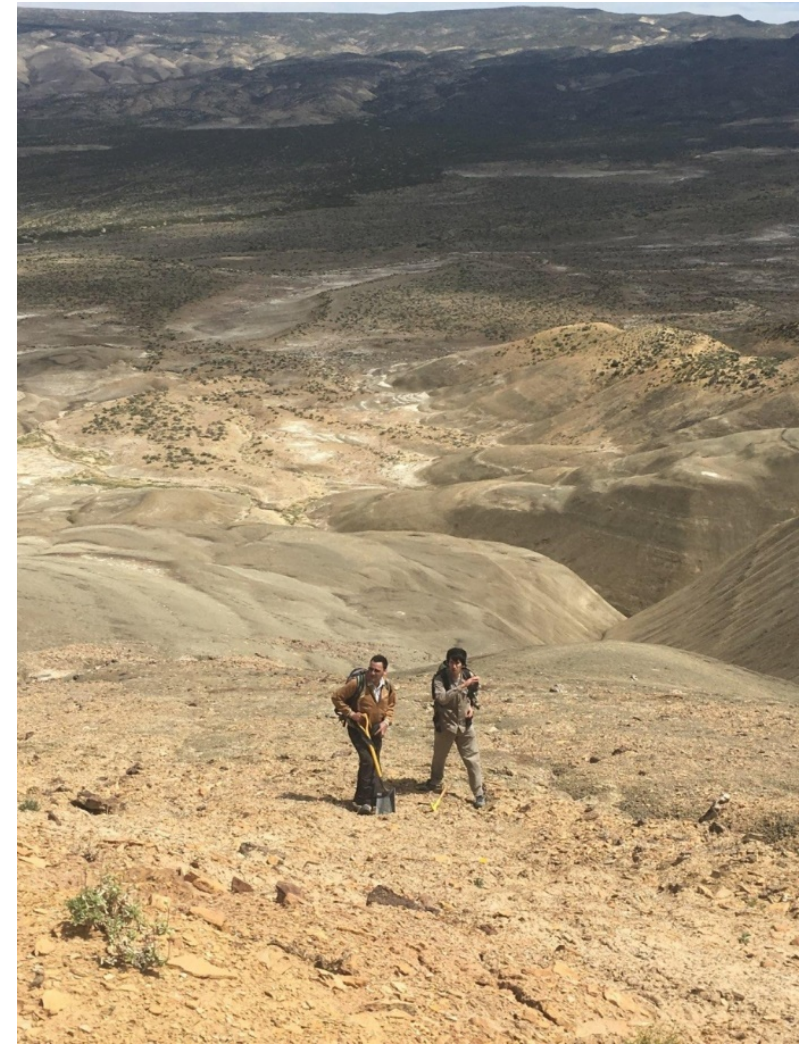

Figure 1: Members of the fieldwork team at La Colonia Formation, Patagonia, Argentina. Photo credit: William Clyde.

\section{structures within the rock), and shocked minerals}

(fractured crystals). Tsunami deposits and spherules are common closer to the impact site, whereas the other markers may be found at locations more distant from the crater. Some methods for finding the K-Pg boundary rely on these features being preserved in the rock. However, many boundary deposits have eroded and are not preserved in the rock, making discovery of the impact layer uncommon.

Another way of finding K-Pg boundary strata uses paleomagnetism. This is the study of the direction and intensity of the magnetic field in the past. It uses the fact that the direction (or polarity) of Earth's magnetic field has flipped back and forth throughout geologic time. For example, the current ("normal") direction of the magnetic field causes a compass needle to point north. However, under conditions of a "reverse" polarity magnetic field, a compass needle would point south.

The K-Pg mass extinction occurred during a period of reverse polarity. These reversals are recorded by magnetic minerals in rocks when they form. The magnetic polarity can be measured in different rock layers and mapped onto the strata to create a numbered series of normal and reverse intervals, which scientists call Chrons (Gradstein et al., 2012). When paleomagnetism is applied to a stratigraphic sequence, as in this research, it is called magnetostratigraphy.

Chron C29r is a reverse polarity interval that encompasses the K-Pg boundary. Chron C29r spans approximately 630,000 years, ending approximately 65.8 million years ago (Clyde et al., 2016). 
Identifying Chron C29r is an effective method of finding the K-Pg boundary interval when rocks do not contain other evidence of the boundary, such as iridium, but do preserve magnetic polarity. Which Chrons are present within the rock layers can be determined based on the approximate age of the formation, as found by other methods such as examining the fossils that are present. This study aimed to look for the presence of Chron C29r, which would indicate the presence of K-Pg boundary strata in La Colonia Formation.

\section{Methods: Collection and Preparation of Samples}

We chose to apply magnetostratigraphy to La Colonia Formation, given the small number of known records and lack of paleomagnetic studies in rocks of this age on the South American continent. This is also the best way to determine if the $\mathrm{K}-\mathrm{Pg}$ boundary is present in this formation, since we are aware of no other clear indicators in the strata, such as the presence of iridium.

Paleomagnetic samples were collected by Dr. Clyde in 2014, 2017, and 2018. The samples collected in 2014 and 2017 were analyzed by other UNH students using the same methods as those described here. The samples from 2017 were collected to obtain higher-resolution data. However, there was an apparent conflict in magnetostratigraphy within the data from the 2014 and 2017 samples. For my project I analyzed the data from samples collected in 2018 to resolve this conflict, determine the presence of Chron C29, and confirm the reconstructed stratigraphy that was determined by the field team.

Geologists construct stratigraphy by determining which rock layers were laid down on top of others and graphing these layers of strata. We sought to reconstruct the stratigraphy at La Colonia assuming the presence of a slumped subsection in the formation, which was first observed during the 2018 fieldwork. This subsection is a group of rock layers that slumped down after they were lithified (or turned into rock).

Typically, sediments are laid down in horizontal layers. In the case of the slumped subsection in La Colonia, where the conflict in the 2014 and 2017 data occurred, some layers moved down on one side relative to the level at which they were initially deposited. This was not noticed by those conducting fieldwork during sample collection in 2014 and 2017, but it was observed during the 2018 fieldwork that this group of layers do not continue horizontally, as was initially assumed.

The samples for this project were chiseled out of the bedrock by Dr. Clyde, with their original orientation, measured with a compass, drawn on the surface. Samples were taken from different sites within the stratigraphy of La Colonia along a ridge over a distance of about half a mile. There were thirty-eight sites total, eleven of which were sampled in 2018. Dr. Clyde collected approximately four fist-size samples per site and brought them back to the rock processing lab at UNH. 
Starting in summer 2019, I cut these samples into $8 \mathrm{~cm}^{3}$ or $1 \mathrm{~cm}^{3}$ cubes to provide a symmetrical sample that could then be measured accurately. I used a bench saw to make large cuts, and a bench sander for finer work. The face of the sample with the orientation drawn on it was preserved (Figure 2). This is very important, because if this orientation had not been preserved, we would not have been able to orient it to determine whether it exhibited normal or reverse polarity.

\section{Methods: Analysis of Samples}

After cutting, I analyzed the 2018 samples in the UNH Paleomagnetism Lab in James Hall. The first technique I used was isothermal remnant magnetization (IRM). Isothermal remnant magnetization is a method used to determine what minerals preserve the magnetic polarity in a sample. These minerals may include magnetite, hematite, and goethite, among others. This analysis is necessary because some minerals (such as goethite) poorly preserve magnetic polarity, which could result in inaccurate data. Therefore, knowing which magnetic minerals are present in a sample tells us how reliable our measurements will be.
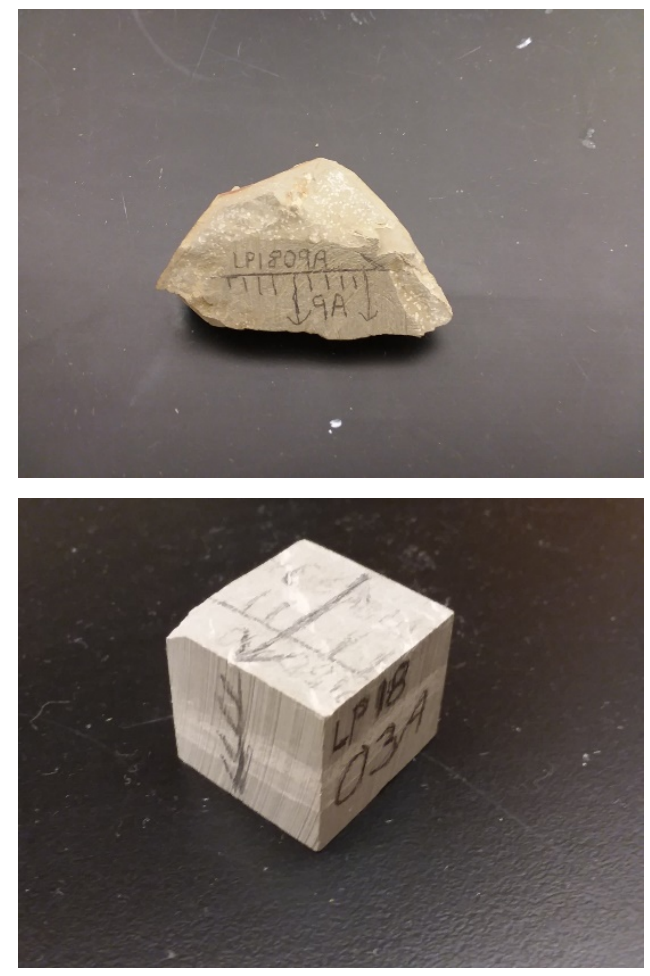

Figure 2: Pictured are an uncut sample as collected in the field (top) and a cut sample showing the sample's orientation (bottom).

To conduct IRM, a strong magnetization is first applied to the

sample using a magnet. The sample is then measured with a Superconducting Quantum Interference Device (SQUID) Rock Magnetometer (Figure 3). The magnetometer is a superconducting instrument, which makes it very sensitive to changes in the magnetization. Therefore, a cage of wires carrying electrical current is placed around the magnetometer to prevent interference from Earth's magnetic field.

The direction and intensity of the sample's IRM as measured by the magnetometer is collected using software called Cryomag (Wack, 2010). This IRM experiment allows us to measure how well the sample preserves magnetic remanence (the original magnetization of the rock). Following the magnetization of the sample, it is then thermally demagnetized, in small steps, in a magnetically shielded oven. Thermal demagnetization applies increasingly higher temperatures to the samples inside a magnetic shield. The temperature at which the rock is demagnetized is indicative of the kind of magnetic minerals that are present (Lowrie, 1990), which helps us know how reliable our natural remnant magnetization (NRM) sample measurements will be. 
After I used IRM to determine which magnetic minerals were present in La Colonia samples, I used step-wise demagnetization of natural remnant magnetization to determine the magnetic polarity of the samples. NRM refers to the magnetism of a rock or sediment, which tells us the Earth's polarity at the time each layer of strata was laid down.

Samples must be analyzed to determine if their specific location in the stratigraphy is part of a normal or reverse polarity Chron. We used the alternating field (AF) method to demagnetize the NRM of three samples per collection site. The samples were placed in an instrument called an AF demagnetizer in which a magnetic field generated by a coiled wire alternates direction periodically

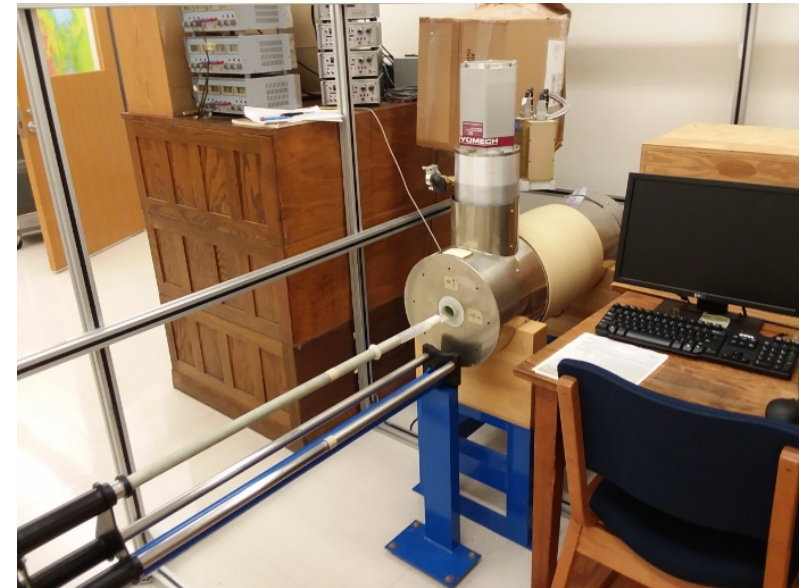

Figure 3: The magnetometer in the UNH Paleomagnetism Lab used to measure rock samples. while the sample is rotated on all axes to make sure that the demagnetization is applied equally to all sides of the sample. This process helps remove secondary components of the NRM (called overprints) to get a more accurate estimate of the original magnetic direction. Overprints may be acquired over time, resulting in a polarity that doesn't accurately reflect the direction of the magnetic field when the rock formed.

The data from the NRM demagnetization are uploaded to a software program called Puffinplot (Lurcock and Wilson, 2012) to determine a site's original polarity, and associate it with a Chron. Once the polarity of the site (normal or reverse) is determined, it can be plotted to see what portions of the formation represent normal or reverse Chrons. This can then be compared with the geomagnetic polarity time scale (or GPTS; Gradstein et al., 2012). The GPTS is an established record that correlates known Chrons to numerical ages, which were determined through other dating methods. Therefore, once a Chron is found, that rock can be correlated to an age, and the presence of Chron C29r can be determined.

\section{Results and Discussion}

Results from the IRM analysis showed that magnetite is the dominant mineral for the dominant rock type in our samples from La Colonia. This type of mineral effectively preserves the original magnetization of the rock, so this indicates that the measurements taken during NRM demagnetization are likely reliable. Results from NRM demagnetization showed that Chron C29r is present within La Colonia, indicating the presence and approximate location of the K-Pg boundary in the strata (Figure 4). 
Chron C29r could be identified because the pattern of normal and reverse intervals we observed could be correlated to the geomagnetic polarity time scale. The known age of the formation (upper Cretaceous to lower Paleogene) allowed for this correlation. However, there are two reverse intervals observed: Chron C29r and Chron C30r. These can be seen in Figure 4 with a normal polarity interval (Chron C30n) between them.

Chron C30r could be distinguished from Chron C29r because of how short it is (about 10,000 years long, whereas Chron C29r is about 630,000 years long) (Clyde et al., 2016). These ages have been determined in the GPTS. The thickness of a section of rock is generally proportional to how long it took for that sediment to be deposited. Therefore, the thickness of the Chrons in the formation indicate how much time they represent. Chron C29r is 12 meters thick, whereas Chron C30r is 8 meters thick; both represent relatively little geological time. Chron C30r

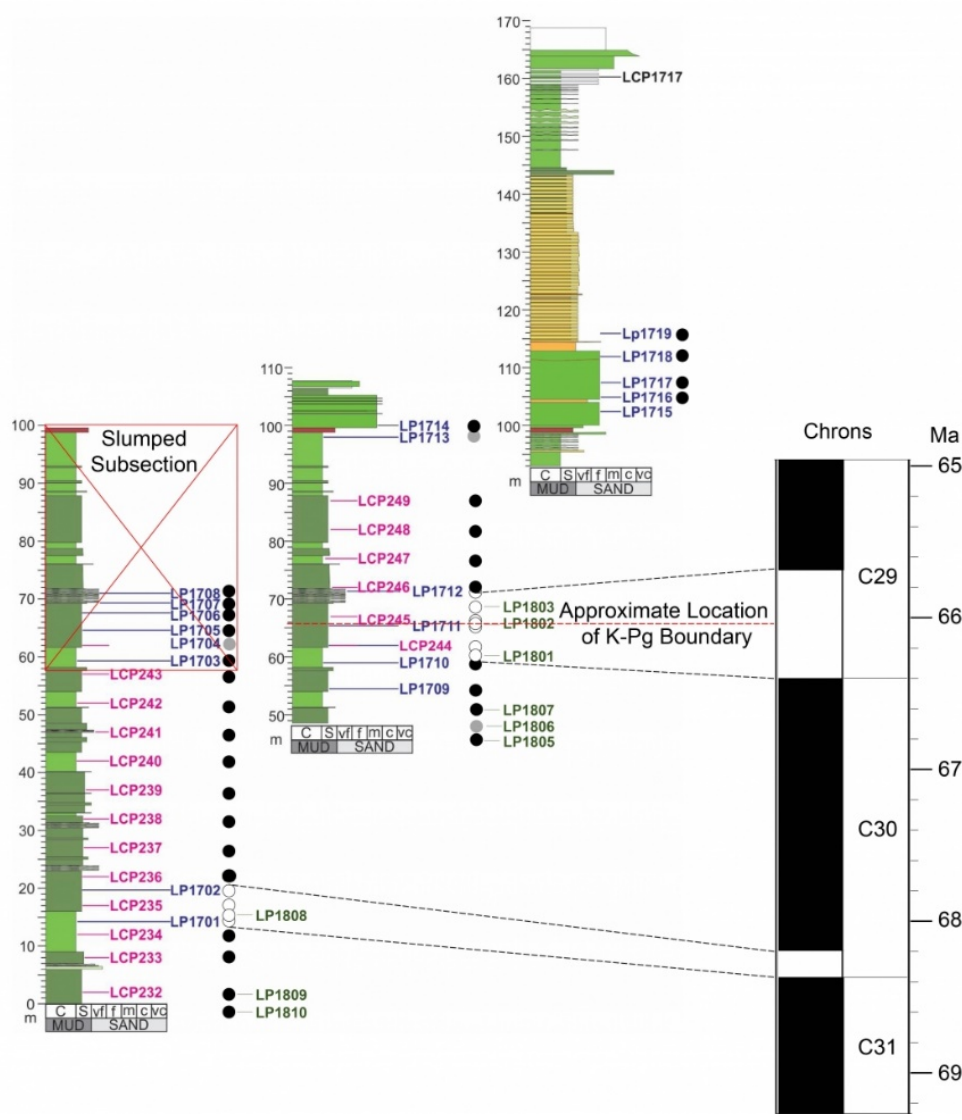

Figure 4: This figure shows the locations of collection sites within La Colonia Formation. The circle next to each site indicates whether it was determined to be normal or reverse polarity (black indicates normal, white indicates reverse, and gray indicates that neither could be clearly determined). The sites within the red box are part of the slumped subsection, and therefore do not count toward the magnetostratigraphy. On the right side of the figure is the series of Chrons preserved in La Colonia, as determined by the polarity of the samples. Again, white represents reverse and black represents normal. is often not preserved because it is so short. However, its presence here gives us a better picture of the timescale of La Colonia. We can now better pinpoint how much time is represented by these rock layers and which ones represent what points in time.

\section{Conclusion}

My results indicate that the K-Pg boundary is present in La Colonia, which is important because it adds another site at which to study the mass extinction in South America. The fossils in La Colonia, such as fossil pollen, leaves, and vertebrates, can now be used in the future to learn about the effects of the Chicxulub impact on the ecosystem in this region. This site will allow us to better understand the effects of the Chicxulub impact on South America, and better understand this event as a whole. 
Through this project I gained a better understanding of the scientific research process. I learned to make measurements using scientific instruments, analyze those data using specialized software, interpret their meaning using my understanding of geology, and present that information to wider audiences. My experience with undergraduate research has motivated me to continue pursuing scientific research in graduate school and in my career. One feature of research that I particularly like is interpreting the data, which in this case tells us something about the history of Earth. Following graduation, I will likely enroll in a graduate program in geology or geosciences, though this may be preceded by work in industry. I plan to continue to use geology as a tool to learn more about Earth's history.

My work with this project will continue by synthesizing data from La Colonia Formation with that of other formations in the coastal Patagonia region. This will result in a magnetostratigraphy that covers a timescale over tens of millions of years, which can be used to precisely date fossils found in the region. I will pursue this research in my remaining time at $\mathrm{UNH}$, and it will culminate in my senior thesis.

I would like to thank Dr. William Clyde for the opportunity to work on this research, as well as his mentorship and support. In addition, thanks to Marcelo Krause, Cody Whelan, and Tyler Smith for their past work on this project. This research was also made possible by funding from the McNair Scholars Program. Thanks to the McNair staff and the summer 2019 McNair cohort, who provided advice, support, and encouragement throughout the research process. In addition, thanks to the professors and graduate students in the Department of Earth Sciences (especially my academic adviser, Dr. Joe Licciardi, and PhD student Sarah Widlansky) for their guidance. Finally, thank you to my family for their support through this process.

\section{References}

Aberhan, M., Weidemeyer, S., Kiessling, W., Scasso, R., and Medina, F., 2007, Faunal evidence for reduced productivity in the Southern Hemisphere Cretaceous-Paleogene boundary sections: Geology, v. 35, p. 227-230, doi: 10.1130/G23197A.1.

Albertão, G., and Martins, P., 1996, A possible tsunami deposit at the Cretaceous-Tertiary boundary in Pernambuco, northeastern Brazil: Sedimentary Geology, v. 104, p. 189-201.

Alvarez, L. W., Alvarez, W., Asaro, F., and Michel, H. V., 1980, Extraterrestrial cause for the Cretaceous-Tertiary extinction: Science, v. 208, p. 1095-1108.

Clyde, W. C., Ramezani, J., Johnson, K. R., Bowring, S. A., and Jones, M. M., 2016, Direct high-precision $\mathrm{U}-\mathrm{Pb}$ geochronology of the end-Cretaceous extinction and calibration of Paleocene astronomical timescales: Earth and Planetary Science Letters, v. 452, p. 272-280, doi:10.1016/j.epsl.2016.07.041.

Cúneo, R. N., Gandolfo, M. A., Zamaloa, M. C., and Hermsen, E., 2014, Late Cretaceous aquatic plant world in Patagonia, Argentina: PLoS One, v. 9, p. 1-18, doi:10.1371/journal.pone.0104749. 
Gradstein, F. M., Ogg, J. G., Schmitz, M. D., Ogg, G. M., 2012, The Geologic Time Scale 2012, Volume 1: Elsevier, $435 \mathrm{p}$.

Hildebrand, A. R., Penfield, G. T., Kring, D. A., Pilkington, M., Camargo Zanoguera, A., Jacobson, S. B., and Boynton, W. V., 1991, Chicxulub crater: A possible Cretaceous/Tertiary boundary impact crater on the Yucatan Peninsula, Mexico: Geology, v. 19, p. 867-871, doi:10.1130/0091-7613(1991)019 2.3.CO;2.

Lowrie, W., 1990, Identification of ferromagnetic minerals in a rock by coercivity and unblocking temperature properties: Geophysical Research Letters, v. 17, p. 159-162, doi:10.1029/GL017i002p00159.

Lurcock, P. C., and Wilson, G. S., 2012, PuffinPlot: A versatile, user-friendly program for paleomagnetic analysis: Technical brief: Geochemistry, Geophysics, Geosystems, v. 13, doi:10.1029/2012GC004098.

Renne, P. R., Arenillas, I., Arz, J. A., Vajda, V., Gilabert, V., and Bermúdez, H. D., 2018, Multi-proxy record of the Chicxulub impact at the Cretaceous Paleogene boundary from Gorgonilla Island, Colombia, v. 46, p. 547-550, doi:10.1130/G40224.1.

Scasso, R., Concheyro, A., Kiessling, W., Aberhan, M., Hecht, L., Medina, F., and Tagle, L., 2005, A tsunami deposit at the Cretaceous/Paleogene boundary in the Neuquén Basin of Argentina: Cretaceous Research, v. 26, p. 283-297, doi:10.1016/j.cretres.2004.12.003.

Schulte, P., et al., 2010, The Chicxulub asteroid impact and mass extinction at the CretaceousPaleogene boundary: Science, v. 327, p. 1214-1218, doi:10.1126/science.1177265.

Wack, M., 2010, A new software for the measurement of magnetic moments using SQUID and spinner magnetometers: Computers \& Geosciences, v. 36, p. 1178-1184, doi:10.1016/j.cageo.2010.05.002.

\section{Author and Mentor Bios}

Peter Haber came to the University of New Hampshire from his hometown of Raymond, New Hampshire, and will graduate in May 2021 with a bachelor of science degree in Earth sciences and a minor in art history. He is enrolled in the McNair Scholars Program and is working toward graduating with an Honors in Major designation. The research on which his article is based was completed mainly as part of a McNair summer research fellowship. His academic adviser, Joe Licciardi, encouraged him to pursue research work with Dr. Will Clyde, who often mentors undergraduates. Peter says that in addition to gaining technical skills in interpreting data and deeper knowledge about subjects such as magnetostratigraphy, his research enabled him to see the full process of research, including presenting results and writing about his research. He has enjoyed learning to write about his field of study for those who do not have a background in geology. After earning his bachelor's degree, Peter plans to attend graduate school for further study in the field of geoscience. 
William Clyde is a professor of geology in the Department of Earth Sciences and has been teaching at the University of New Hampshire since 1998. He specializes in geology, Earth history, and paleontology. Dr. Clyde has been collaborating with colleagues in Argentina since 2008 to better understand the interval of time from about 68 to 50 million years ago, which encompasses the $\mathrm{K}-\mathrm{Pg}$ mass extinction and the Early Eocene Climate Optimum, one of the warmest intervals of Earth's history. After several seasons of fieldwork for this project, Dr. Clyde and his colleagues encountered some perplexing results. Peter's work helped to unravel the problem and determine that one of the sites was not in its original geological position and thus not a reliable place to collect data. According to Dr. Clyde, "Working with undergraduates on research is always very valuable, as their passion for learning is palpable in a research setting like this, and I inevitably learn something new about the project from their fresh, unbiased perspective." Dr. Clyde mentors undergraduate researchers in his lab every year. Peter is the second of them to write for Inquiry. Dr. Clyde believes that "the ability to communicate scientific results to a broader audience is an increasingly essential skill for any scientist, so working on this early in a student's career is of real value."

Copyright 2020, Peter Haber 